\title{
Safety and Efficacy of Nontherapeutic Male Circumcision: A Systematic Review
}

\author{
Caryn L. Perera, BA, Grad Cert EBP \\ Franklin H. G. Bridgewater, \\ MBBS, FRACS ${ }^{2}$ \\ Prema Thavaneswaran, BSc (Hons), \\ $P h D^{1}$
}

Guy J. Maddern PbD, FRACS',2,3

${ }^{1}$ ASERNIP-S, Royal Australasian College of Surgeons, Adelaide, South Australia, Australia

${ }^{2}$ Department of Surgery, The Queen Elizabeth Hospital, Adelaide, South Australia, Australia

${ }^{3}$ Department of Surgery, The University of Adelaide, Adelaide, South Australia, Australia

\begin{abstract}
PURPOSE We wanted to assess the safety and efficacy of nontherapeutic male circumcision through a systematic review of the literature.

METHODS We systematically searched The York Centre for Reviews and Disseminations, Cochrane Library, PubMed, and EMBASE databases for randomized controlled trials published between January 1997 and August 2008. Studies reporting on circumcision in an operative setting in males of any age with no contraindications to or medical indications for circumcision were eligible for inclusion. The main comparator was intact genitalia. From 73 retrieved studies, 8 randomized controlled trials were ultimately included for analysis.
\end{abstract}

RESULTS Severe complications were uncommon. Analgesia/anesthesia during circumcision was promoted. The prevalence of self-reported genital ulcers was significantly lower in circumcised men than uncircumcised men (3.1\% vs 5.8\%; prevalence risk ratio $0.53 ; 95 \%$ confidence interval $[\mathrm{Cl}], 0.43-0.64 ; P<.001)$. Circumcised sub-Saharan African men were at significantly lower risk of acquiring human immunodeficiency virus/acquired immune deficiency syndrome than were uncircumcised men (random effects odds ratio $=0.44,95 \% \mathrm{Cl}, 0.32-0.59$; $P<.001)$. The evidence suggests that adult circumcision does not affect sexual satisfaction and function.

CONCLUSIONS Strong evidence suggests circumcision can prevent human immunodeficiency virus/acquired immune deficiency syndrome acquisition in subSaharan African men. These findings remain uncertain in men residing in other countries. The role of adult nontherapeutic male circumcision in preventing sexually transmitted infections, urinary tract infections, and penile cancer remains unclear. Current evidence fails to recommend widespread neonatal circumcision for these purposes.

Ann Fam Med 2010;8:64-72. doi:10.1370/afm.1073.

\section{INTRODUCTION}

M ale circumcision is the most commonly performed surgical procedure in the world. ${ }^{.}$The procedure may be performed to treat an underlying pathological process (therapeutic circumcision) or for prophylactic, religious, cultural, or social reasons (nontherapeutic circumcision). This systematic review seeks to assess the safety and efficacy of nontherapeutic male circumcision through a systematic review of the literature.

The prepuce may protect the glans by acting as a barrier against contamination $^{2}$ and maintaining a moist environment for the glans, ${ }^{3}$ and its complex innervation suggests that it may also enhance sexual pleasure. ${ }^{2}$ At birth the prepuce is usually not retractable. Growth of the penis, accumulation of epithelial dermis, and erectile activity during the first 3 or 4 years of life eventually allows retraction. ${ }^{4}$ Circumcision (removal of the prepuce) usually takes place in a day-surgery setting. The surgical technique is determined by the social circumstances, together with the indication for the operation and the patient's age. Major complications associated with circumcision may include hemorrhage, sepsis, fistula, 
meatal stenosis, removal of excessive skin, and penile loss. ${ }^{5}$ Adverse psychosocial effects may include dissatisfaction with circumcision, castration anxiety, and a heightened pain response..$^{5-8}$

Nontherapeutic male circumcision, by definition, does not treat an underlying pathological process, and motivations for the procedure may be religious, cultural, social, or prophylactic. Religious male circumcision, which is practiced under both Jewish and Islamic law, allows individuals to participate fully in their religion. Circumcision is also integral to the culture of some Australian Aboriginal, Filipino, Korean, Turkish, and African groups. Social motivations may include a desire to resemble other family members or a perception of greater penile hygiene. ${ }^{7,9}$ Finally, circumcision has been widely debated as a preventive measure for sexually transmitted infection, human immunodeficiency virus/acquired immune deficiency syndrome (HIV/AIDS), penile cancer, and urinary tract infection. It is unclear whether maintaining excellent penile hygiene can also confer a protective effect. ${ }^{3,10}$

\section{METHODS}

\section{Inclusion Criteria}

Eligible studies were those reporting on circumcision in an operative setting in male patients of any age, with no contraindications to or medical indications for circumcision. Generally, the main comparator was intact genitalia. To assess the effect of circumcision on subsequent pain response, however, it was necessary to include studies where all patients were circumcised. The clinical efficacy outcomes assessed were the incidence of sexually transmitted infection, urinary tract infection, HIV/AIDS, and penile cancer. Safety and patient-reported outcomes were also assessed.

\section{Search Strategy and Selection Criteria}

Only randomized controlled trials (RCTs) were included for analysis in this level-1 systematic review. Research articles were excluded if they reported solely on cost-effectiveness analyses or methodological issues. The reviewers believed that 1997 was an appropriate date limit, as a comprehensive review was performed in 1996 by the Canadian Paediatric Society. ${ }^{11}$ It was deemed not useful to duplicate this summary of the literature; hence, studies were restricted to those published in English from January 1997 to August 2008 (Table 1).

RCTs were retrieved when they were judged to possibly meet the inclusion criteria. These criteria were then applied fully to the retrieved studies to identify those to be appraised and included in the review. RCTs that did not meet the inclusion criteria were excluded.

\section{Data Extraction and Synthesis}

Data from all included RCTs were extracted by 1 reviewer and checked by a second reviewer using standardized data extraction tables that were developed a priori, with any differences resolved through discussion. The included RCTs were classified according to the National Health and Medical Research Council hierarchy of evidence. ${ }^{2}$ An analysis of the methodological quality was undertaken with regard to such factors as randomization, blinding, and sample size.

Formal statistical pooling (meta-analysis) was only performed if 2 or more RCTs addressed the same comparison, with data available for comparable outcomes. A test for statistical heterogeneity was then performed, with $P<.10$ chosen to indicate statistical heterogeneity. Using RevMan (the Cochrane Information Management System Review Manager software, http://www. ims.cochrane.org/revman), relative risks (random effects model) with $95 \%$ confidence intervals (CIs) were calculated for dichotomous outcomes, and the data for outcomes that were not suitable for statistical pooling were reported narratively.

\section{RESULTS}

Approximately 1,200 potentially relevant studies were identified from the search strategy 73 were retrieved for further consideration, and 65 were subsequently excluded. Of the excluded studies, 49 (75.4\%) were concerned solely with pain relief, 4 (6.2\%) compared various surgical techniques, 11 (16.9\%) were therapeutic male circumcision, and 1 was a clinical trial simulation (1.5\%). Eight RCTs ${ }^{8,13-19}$ were eligible for appraisal and inclusion in this systematic review (Figure 1).

\begin{tabular}{|c|c|}
\hline Databases Searched & Search Terms \\
\hline $\begin{array}{l}\text { The York (UK) Centre for Reviews } \\
\text { and Dissemination (CRD) }\end{array}$ & $\begin{array}{l}\text { Medical subject heading } \\
(\mathrm{MeSH}) \text { : circumcision, male }\end{array}$ \\
\hline The Cochrane Library & Textword terms: \\
\hline PubMed & circumcis* \\
\hline \multirow[t]{8}{*}{ EMBASE } & bris \\
\hline & milah* \\
\hline & mohel $^{*}$ \\
\hline & khitan* \\
\hline & dhapi* \\
\hline & djapi* \\
\hline & mandiwa* \\
\hline & mandiyala* \\
\hline \multicolumn{2}{|c|}{$\begin{array}{l}\text { Bris, milah, and mohel are terms associated with Jewish religious circumcision; } \\
\text { khitan is a term for Islamic religious circumcision; and dhapi, djapi, madiwa, } \\
\text { and mandiyala are terms for Australian Aboriginal circumcision. The trunca- } \\
\text { tion symbol (*) is used in many databases to allow retrieval of search terms } \\
\text { with common word stems, eg, circumcis* will retrieve circumcise, circumcised, } \\
\text { circumcision, etc. }\end{array}$} \\
\hline
\end{tabular}




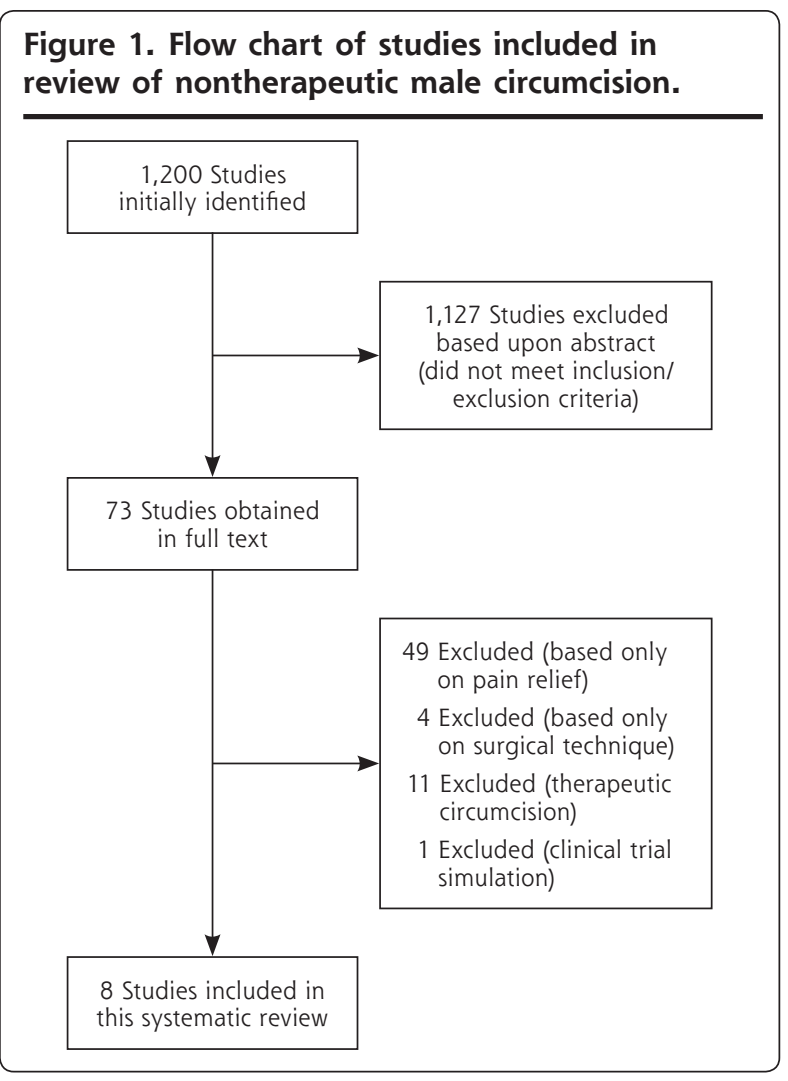

Tables 2 and 3 display the characteristics of the included studies. This systematic review reports neonatal outcomes and adult outcomes separately.

\section{Neonatal Nontherapeutic Male Circumcision RCTs}

Two studies reported upon neonatal circumcision. Taddio et $\mathrm{al}^{8}$ reported upon the effect neonatal circumcision had upon subsequent pain response at vaccination and Macke $^{19}$ reported upon the relationship between neonatal circumcision and pain distress/maternal-infant bonding.

\section{Safety Outcomes}

Neither study reported mortality related to the circumcision procedure in neonates. Additionally, no perioperative adverse events were reported in the 2 studies that assessed neonatal circumcision.

\section{Pain Perception}

One $\mathrm{RCT}^{19}$ reported measured pain distress using heart rate and "percentage of cry" for 60 neonates receiving either analgesia or placebo for neonatal circumcision. Both arms of the trial reported significant increases in heart rate and "percentage of cry" from precircumcision to circumcision $(P<.01)$ with no sig-

Table 2. Studies Included in the Review of Nontherapeutic Male Circumcision

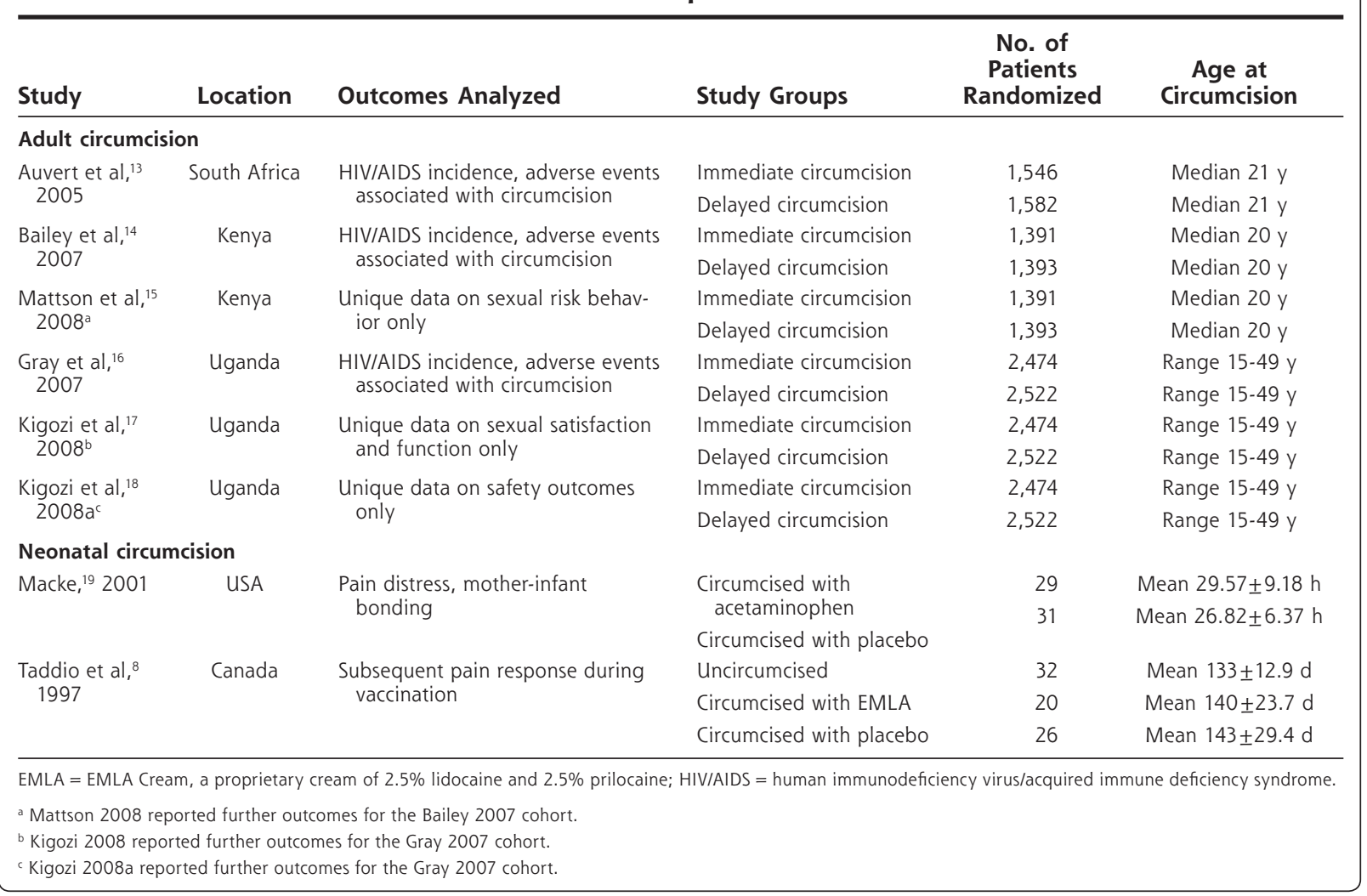


nificant differences between the groups during the circumcision. From precircumcision to postcircumcision, the placebo group reported a significant increase in "percentage of cry" $(P<.01)$. The "percentage of cry" after circumcision was significantly higher in the placebo group than the analgesia group $(P<.05)$, suggesting an effect from the analgesia.

Significantly more infants who received analgesia showed continued alertness after circumcision when compared with infants who received placebo $(P=.01)$. The authors suggested that stress may provoke an elevation of cortisol, which, as it decreases, may cause infants to become drowsy and possibly mask pain.

\section{Clinical Efficacy}

No RCTs that reported on the association between neonatal nontherapeutic circumcision and sexually transmitted infection, penile cancer, urinary tract infection, or HIV/AIDS could be identified.

Other Considerations: Mother-Infant Interaction One RCT ${ }^{19}$ measured mother-infant interactions before and after neonatal nontherapeutic male circumcision. Sixty neonates received either analgesia or placebo at circumcision and behaviors were measured before and after circumcision.

Infant behavior scores decreased in both groups from before to after the circumcision, and the decrease was greater in infants who received placebo $(P<.01)$. Mothers of infants in the analgesia group showed an increase in a social and emotional growth-fostering behaviors score from before to after circumcision, whereas the score for the mothers of infants in the placebo group declined $(P<.05)$.

\section{Description of Adult Nontherapeutic Male Circumcision RCTs}

Three studies reported upon circumcision in adult men, specifically the efficacy of circumcision for preventing HIV/AIDS acquisition in sub-Saharan African men. ${ }^{13,14,16}$ Three studies ${ }^{15,17,18}$ reported further unique outcomes for the Bailey et $\mathrm{al}^{14}$ and Gray et $\mathrm{al}^{16} \mathrm{RCT}$ cohorts. Mattson et $\mathrm{al}^{15}$ reported sexual risk behavior outcomes, whereas Kigozi et al ${ }^{17,18}$ reported safety and sexual satisfaction and function outcomes.

Another study ${ }^{21}$ also reported on the Bailey et $\mathrm{al}^{14}$ cohort and included data for a further 141 men originally randomized to the control group who received circumcision at the 2-year follow-up. As outcomes were not reported separately for these 141 patients, it was not possible to discern outcomes for those originally randomized to the circumcision group, so this study was methodologically ineligible for inclusion in this systematic review.

\section{Safety Outcomes}

Three RCTs $s^{13,14,18}$ reported 251 perioperative adverse events in 5,228 patients (4.8\%) aged between 15 and 49 years (Table 4 ). One $\mathrm{RCT}^{13}$ reported the outcome 21 months after surgery; 11 adverse events were reported in 1,131 adult patients $(0.97 \%)$, including problems with urinating (3 patients, $0.26 \%$ ), dissatisfaction with the appearance of the penis (4 patients, $0.35 \%)$, and mild or moderate erectile dysfunction (4 patients, $0.35 \%)$.

Two studies ${ }^{14,18}$ reported on short-term postoperative wound healing. One $\mathrm{RCT}^{14}$ reporting on 1,282 of 1,334 men who had been circumcised (96\%) found that the wound was completely healed at 30 days after surgery in 1,266 (98.8\%) patients, and that by 3 months all wounds had healed completely. Another RCT ${ }^{18}$ reporting on 2,258 of 2,326 men who were circumcised $(97 \%)$ found that at 6 weeks after surgery, 2,163 $(95.8 \%)$ patients had complete wound healing.

One study ${ }^{18}$ examined the effect of early resumption of intercourse. This study reported a significantly higher incidence of adverse events in those individuals who resumed intercourse before healing was complete; however, the level of statistical significance was not reported.

\section{Pain Perception}

Three RCTs ${ }^{13,14,18}$ reported on pain associated with adult nontherapeutic male circumcision. Of 5,228 circumcised men, pain was reported in 710 men (13.5\%). Only Bailey et $\mathrm{al}^{14}$ reported on the severity of pain, however. They found that of the 1,391 patients enrolled, 690 (49.6\%) experienced very mild pain. At 8 day follow-up 148 patients (10.64\%) reported very mild pain and the remaining patients reported no pain.

\section{Clinical Efficacy}

Two RCTs ${ }^{15,16}$ reported on the efficacy of adult nontherapeutic male circumcision for preventing sexually transmitted infections. One RCT ${ }^{16}$ found that the prevalence of self-reported genital ulcers was significantly lower in the circumcised group than in the uncircumcised group (3.1\% vs $5.8 \%$; prevalence risk ratio $0.53,95 \% \mathrm{CI}, 0.4$ $0.64, P<.001)$. The other study ${ }^{15}$ found that circumcised men were more likely than uncircumcised men to have a prevalent infection diagnosed at baseline $(P=.02)$ and an incident infection diagnosed at the 6 -month follow-up $(P=.05)$. At the 12 -month follow-up there were no significant differences between the proportions of circumcised and uncircumcised men with incident sexually transmitted infections. ${ }^{15}$

No RCTs that reported on the association between nontherapeutic male circumcision and penile cancer or urinary tract infections could be identified. 


\begin{tabular}{|c|c|c|c|c|c|}
\hline Study & $\begin{array}{l}\text { Randomization } \\
\text { Technique }\end{array}$ & $\begin{array}{l}\text { Outcome } \\
\text { Assessors } \\
\text { Blinded }\end{array}$ & $\begin{array}{l}\text { Inclusionl } \\
\text { Exclusion } \\
\text { Criteria } \\
\text { Provided }\end{array}$ & Operator & Baseline Characteristics \\
\hline \multicolumn{6}{|c|}{ Adult circumcision } \\
\hline $\begin{array}{l}\text { Auvert et al, }{ }^{13} \\
2005\end{array}$ & $\begin{array}{l}\text { Opaque, sealed } \\
\text { envelopes }\end{array}$ & Yes & Yes & $\begin{array}{l}\text { General practi- } \\
\text { tioners experi- } \\
\text { enced in male } \\
\text { circumcision }\end{array}$ & $\begin{array}{l}\text { Patients in both groups well matched for age, } \\
\text { religion, ethnic group, and educational level; } \\
\text { authors did not provide information on statistical } \\
\text { significance }\end{array}$ \\
\hline $\begin{array}{l}\text { Bailey et al, }{ }^{14} \\
2007^{a}\end{array}$ & $\begin{array}{l}\text { Opaque, sealed } \\
\text { envelopes }\end{array}$ & Yes & Yes & Clinicians & $\begin{array}{l}\text { Patients in both groups well matched for demo- } \\
\text { graphic and physical characteristics, prevalence }\end{array}$ \\
\hline \multicolumn{2}{|l|}{$\begin{array}{l}\text { Mattson et al, }{ }^{15} \\
2008\end{array}$} & & & & $\begin{array}{l}\text { of STI, and reported sexual history with women; } \\
\text { authors did not provide information on statistical } \\
\text { significance }\end{array}$ \\
\hline $\begin{array}{l}\text { Gray et al }{ }^{16} \\
2007^{a}\end{array}$ & $\begin{array}{l}\text { Opaque, sealed } \\
\text { envelopes }\end{array}$ & NR & Yes & $\begin{array}{l}\text { Trained and } \\
\text { certified }\end{array}$ & $\begin{array}{l}\text { Patients in both groups well matched for sociodemo- } \\
\text { graphic characteristics, sexual risk behaviors, rates }\end{array}$ \\
\hline \multicolumn{2}{|l|}{$\begin{array}{l}\text { Kigozi et al, }{ }_{1}^{17} \\
2008\end{array}$} & & & physicians & $\begin{array}{l}\text { of self-reported symptoms of STI; authors did not } \\
\text { provide information on statistical significance }\end{array}$ \\
\hline \multicolumn{2}{|l|}{$\begin{array}{l}\text { Kigozi et al, }{ }^{18} \\
2008^{\mathrm{a}}\end{array}$} & & & & $\begin{array}{l}\text { Previous receipt of voluntary counselling and testing } \\
\text { slightly higher in intervention than control groups } \\
\text { (no figures provided) }\end{array}$ \\
\hline \multicolumn{6}{|c|}{ Neonatal circumcision } \\
\hline Macke ${ }^{19} 2001$ & $\begin{array}{l}\text { Groups determined by } \\
\text { pharmacy staff }\end{array}$ & Yes & $\begin{array}{l}\text { Inclusion } \\
\text { criteria } \\
\text { only }\end{array}$ & $\begin{array}{l}\text { Private and resi- } \\
\text { dent physicians }\end{array}$ & $\begin{array}{l}\text { No significant differences between the groups for } \\
\text { maternal or newborn variables }\end{array}$ \\
\hline $\begin{array}{l}\text { Taddio et al, }{ }^{8} \\
1997\end{array}$ & $N R^{b}$ & Yes & No & Pediatricians & $\begin{array}{l}\text { No significant differences between groups for demo- } \\
\text { graphic characteristics }\end{array}$ \\
\hline
\end{tabular}

\begin{tabular}{|lr|}
\hline \multicolumn{2}{l}{ Table 4. Adverse Events Reported in } \\
Men Aged 15 to 49 Years Who Received \\
Circumcision (N= 5,228) \\
\hline Adverse Events & No. (\%) \\
\hline Postoperative bleeding & $69(1.32)$ \\
Infection & $77(1.47)$ \\
Wound disruptions & $34(0.65)$ \\
Delayed healing & $5(0.10)$ \\
Swelling or hematoma & $12(0.23)$ \\
Anesthesia-related & $2(0.04)$ \\
Damage to the penis & $4(0.08)$ \\
Insufficient skin removed & $4(0.08)$ \\
Problems with appearance & $9(0.17)$ \\
Difficulty voiding & $7(0.13)$ \\
Other causes & $28(0.54)$ \\
Total & $251(4.8)$ \\
\hline
\end{tabular}

Three RCTs ${ }^{13,14,16}$ reported on HIV/AIDS acquisition after adult nontherapeutic male circumcision in sub-Saharan African men. As studies were homogeneous, a meta-analysis was performed controlling for those who were found to have been HIV positive at baseline (Figure 2). Circumcised men in this population were at significantly lower risk of acquiring $\mathrm{HIV} /$ AIDS (random effects $\mathrm{OR}=0.44,95 \% \mathrm{CI}, 0.32-0.59$;
$P<.001)$. All 3 RCTs were stopped by their data- and safety-monitoring boards before their designed completion because of significant reductions in HIV/AIDS incidence in the circumcision groups. It was deemed unethical to continue without offering circumcision to control group participants. ${ }^{22}$

\section{Other Considerations}

One $\mathrm{RCT}^{14}$ found that of the 1,333 circumcised men interviewed 3 days postsurgery, all those who were employed reported that they had resumed working, and 1,287 (96\%) reported having returned to normal activities by this time. By 8 days postcircumcision, all but 1 patient had returned to normal activities.

Two RCTs $\mathrm{s}^{13,14}$ reported on satisfaction with circumcision. One $\mathrm{RCT}^{14}$ reported that of the 1,281 patients examined at 30 days, $1,274(99.5 \%)$ men were very satisfied and $6(0.5 \%)$ were somewhat satisfied with their circumcision. The remaining patient, who reported being somewhat dissatisfied at 1 month after circumcision, complained of weak erections, which resolved at subsequent visits. Similarly, in the other RCT, ${ }_{1}^{13} 98.5 \%$ of circumcised men were very satisfied with the result of their circumcision at 3-month follow-up.

One $\mathrm{RCT}^{17}$ found that from baseline to 24 -month follow-up sexual satisfaction did not significantly 


\begin{tabular}{|c|c|c|}
\hline Power Calculations & Follow-Up & $\begin{array}{l}\text { Lost to Follow-Up } \\
\text { No. (\%) }\end{array}$ \\
\hline $\begin{array}{l}3,035 \text { patients required } \\
\text { to obtain power of } \\
80 \% \text { to detect } 50 \% \\
\text { reduction in HIV }\end{array}$ & $21 \mathrm{mo}$ & $\begin{array}{l}251(8) \\
100(6.5 \%) \text { in circumcision group } \\
151(9.5) \text { in control group ( } P=.0016) \text {. }\end{array}$ \\
\hline $\begin{array}{l}\text { 2,776 patients required } \\
\text { to detect } 50 \% \text { dif- } \\
\text { ference in } 2-y \text { HIV } \\
\text { seroincidence }\end{array}$ & $24 \mathrm{mo}$ & $\begin{array}{l}240(8.6) \\
126(9.1) \text { in circumcision group } \\
114(8.2) \text { in control group }\end{array}$ \\
\hline $\begin{array}{l}\text { Study had } 80 \% \text { power } \\
\text { to detect rate ratio of } \\
0.5 \text { for incident HIV in } \\
\text { intervention group rel- } \\
\text { ative to control group }\end{array}$ & $24 \mathrm{mo}$ & $\begin{array}{l}229(10.4) \\
114(10.4) \text { in circumcision group } \\
115(10.4) \text { in control group }\end{array}$ \\
\hline NR & 1-h post circumcision & NR \\
\hline $\begin{array}{l}30 \text { infants per group } \\
\text { needed }\end{array}$ & $\begin{array}{l}20 \mathrm{sec} \text { before, } 20 \mathrm{sec} \\
\text { during, and } 20 \mathrm{sec} \\
\text { after vaccination }\end{array}$ & NR \\
\hline
\end{tabular}

change in circumcised men but significantly increased in uncircumcised men $(P<.001)$. Further, uncircumcised men reported significantly greater sexual satisfaction than circumcised men at both a 12 -month $(P=.007)$ and 24-month $(P=.004)$ follow-up. This improvement may have been due to the health education and medical care provided to all trial participants.

Uncircumcised men reported significantly fewer erectile problems at a 24 -month follow-up than at enrollment $(P<.001)$, and there was no significant difference in erectile problems between the 2 groups at a 24 -month follow-up. Both groups reported significantly fewer difficulties with penetration at a 24 -month follow-up than at enrollment $(P<.001)$, and circumcised men reported less dyspareunia at a 24-month follow-up than at baseline $(P<.001)$. A significantly higher proportion of circumcised men reported difficulty with penetration $(P=.02)$ and experienced more pain during or after intercourse $(P=.05)$ compared with uncircumcised men at the 6-month follow-up.

One $\mathrm{RCT}^{16}$ did not find any significant changes in sexual behavior after circumcision. One RCT ${ }^{14}$ found that from baseline to 24-month follow-up, uncircumcised men practiced significantly safer behaviors regarding unprotected sexual intercourse $(P=.035)$ and consistent condom use $(P=.033)$. In a subset of this cohort of individuals, ${ }_{1}^{15}$ median risk scores declined for both circumcised and uncircumcised men; and after adjusting for confounding, there was a significant decline in sexual risk scores at the 6 - and 12-month follow-up visits compared with baseline ( $P$ values not stated). At a 12 -month follow-up there was no significant difference in the sexual risk scores of circumcised and uncircumcised men.

\section{DISCUSSION}

To our knowledge, this systematic review is the first of adult and neonatal nontherapeutic male circumcision

\section{Figure 2. Efficacy of circumcision in preventing HIV infection in men who were HIV-negative at} randomization.

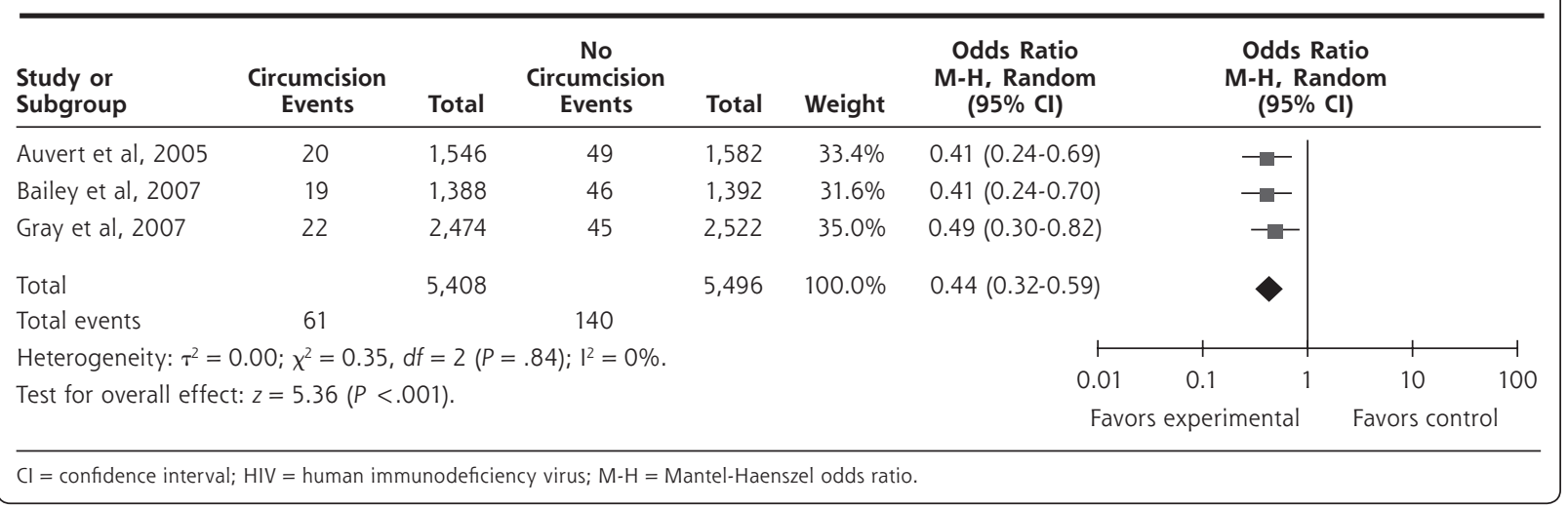


to include safety and efficacy outcomes from 3 recent landmark RCTs. ${ }^{13,14,16}$ Uniquely, other relevant outcomes, such as sexual function and behavioral change, have also been considered.

\section{Study Limitations}

There was a paucity of RCT evidence upon which to draw conclusions. Further, not all outcomes were reported in all RCTs, and several outcomes were not reported uniformly. It is internationally recommended that circumcisions should be performed in a surgical setting, ${ }^{1,23}$ and this systematic review considered circumcision only in such a setting. It is likely that circumcisions performed in unhygienic conditions and with little or no postoperative care would have higher adverse events. ${ }^{24}$ Mass circumcisions performed using a common instrument may also have associated morbidity.

Another limitation may have been any introduced performance bias in that some outcome assessors were not blinded to circumcision status. Importantly, only 5 of the 8 included randomized cohorts reported that their outcome assessors were blinded.

\section{Neonatal Circumcision}

No reports of mortality or adverse events resulting from the procedure itself were found in any of the included studies. Pain control is advocated, as neonates circumcised with analgesia can experience significantly less postoperative pain distress than those circumcised with placebo. ${ }^{19}$ Further, neonatal circumcision performed without pain relief may affect neonatal behavior, interfere with maternal-infant interaction, ${ }^{19}$ and cause increased responses to subsequent pain. ${ }^{8}$

\section{Adult Circumcision}

No reports of mortality due to the procedure itself were found in any of the included studies. The reported adverse effects in adult circumcisions were infrequent, suggesting that circumcision in this population can be performed safely. Studies differed in the manner in which adverse events were defined, detected, and reported, yet severity of complications were generally reported as mild to moderate, and most resolved within hours or days. Serious, permanent adverse effects, such as erectile dysfunction, occurred rarely.

Adult circumcision may potentially have more associated adverse events than childhood or neonatal circumcision, as adult circumcisions usually require surgical wound suturing. Complications can occur if patients resume intercourse before wound healing. ${ }^{24,18}$ Various age-dependent factors, such as the type of anesthesia or surgical technique used, and skills of the circumciser (clinical vs nonclinical traditional circumciser) may also affect outcomes.

As safety outcomes were reported only for subSaharan African adults with strict inclusion criteria, the adverse events reported may not reflect the broader population with a wider range of comorbidities. Some patient groups have contraindications to circumcision, including patients with congenital anomalies of the penis, chordee, buried penis, or patients with a family history of a bleeding disorder. ${ }^{10}$

One RCT ${ }^{16}$ found that circumcision can protect men against genital ulcers and postulated that it could be protective against cutaneously acquired infections but may not protect against urethral infections. It is difficult to assess this statement, as no other sexually transmitted infections were reported upon in the RCT literature.

In developed countries penile cancer is a relatively rare disease, with an incidence of approximately 1 in 100,000. ${ }^{10}$ The absence of RCT evidence, combined with the rarity of penile cancer, suggests that circumcision is not justified for the sole purpose of protecting against penile cancer. ${ }^{10}$

The presence of uropathogens is thought to be a risk factor for urinary tract infection, as uropathogens may attach to the foreskin and reach the renal tract via the ascending route. ${ }^{10}$ The absence of RCT evidence, in addition to the incidence of urinary tract infection in normal boys of approximately $1 \%$ to $2 \%$, makes it unlikely that preventive circumcision of normal boys would outweigh the adverse events associated with the procedure. ${ }^{10,11}$

A meta-analysis found that circumcised sub-Saharan African men had a significantly lower risk of acquiring HIV/AIDS after nontherapeutic male circumcision. It is not clear whether the findings from these African trials can be extrapolated to other countries with ready access to condoms and a lower prevalence of HIV/AIDS.

Several biologic mechanisms for a protective effect of circumcision for HIV/AIDS infection have been proposed. For example, the prepuce contains a high density of Langerhans cells, which express HIV-1 receptors. By removing this source of Langerhans cells, circumcision could potentially reduce the risk of HIV/AIDS acquisition and transmission. ${ }^{25-27}$ The prepuce may be susceptible to mild trauma during intercourse, facilitating transmission of infection, ${ }^{28}$ whereas the warm and moist environment under the prepuce is also thought to be conducive to prolonged viral survival. ${ }^{27,28}$ Finally, the layer of keratin that develops in a circumcised penis may provide additional defense against infection. ${ }^{26}$ In contrast, a protective effect of the prepuce for HIV/AIDS infec- 
tion has been suggested. The apocrine glands in the inner prepuce secrete a lysozyme that reportedly kills HIV-1 in vitro. ${ }^{29}$ The immunological effects of subpreputial flora, secretory immunoglobulins, and lytic secretions from the prostate, urethra, and seminal residues are unclear. ${ }^{28}$ Finally, the prepuce may reduce the likelihood of abrasions occurring during intercourse, thereby removing a potential site for viruses to enter the body. ${ }^{28}$

The evidence did not show a decrease in sexual satisfaction and function after circumcision. Interestingly, uncircumcised men showed significant increases from baseline to 2-year follow-up for most measures of satisfaction and function, which may be due to the health education and medical care provided during the study. ${ }^{17}$ Overall the frequency of most problems either did not change or diminished during the followup period, and problems were rare (less than $2 \%$ ) at all time points. The difficulties with penetration and pain experienced after circumcision may have been transient problems caused by incomplete keratinization of the scar. ${ }^{17}$

\section{Research Recommendation}

Although approximately $30 \%$ of the global male population is circumcised, there is a paucity of high-quality evidence. ${ }^{24}$ Depending on the indication under investigation, prospective RCTs and case-control studies should be conducted to strengthen the evidence base and allow more informed conclusions on nontherapeutic male circumcision to be drawn.

Although the evidence for the efficacy of adult nontherapeutic male circumcision in preventing HIV/AIDS acquisition in sub-Saharan African men is strong, it is unclear whether these findings can be extrapolated to male populations in other countries. The role of adult nontherapeutic male circumcision in preventing sexually transmitted infection, urinary tract infection, and penile cancer is less clear, whereas the role of neonatal circumcision in preventing HIV/AIDS, sexually transmitted infection, urinary tract infection, and penile cancer is not presently supported by RCT evidence.

Patients who request circumcision in the belief that it bestows clinical benefits must be made aware of the lack of consensus and robust evidence, as well as the potential medical and psychosocial harms of the procedure. As the efficacy of prophylactic nontherapeutic male circumcision has not been comprehensively studied in neonates, it would be inappropriate to recommend widespread neonatal circumcision for this purpose.

To read or post commentaries in response to this article, see it online at http://www.annfammed.org/cgi/content/full/8/1/64.
Key words: Circumcision, male; sexually transmitted diseases; HIV; acquired immunodeficiency syndrome; penile cancer; urinary tract infections; prophylactic procedures

Submitted January 13, 2009; submitted, revised, April 22, 2009; accepted May 11, 2009.

Funding support: This work was funded by a grant from the Australian Government Department of Health and Aging and the South Australian Department of Health.

\section{References}

1. Godbole P, Duffy P, Boddy S-A, et al. Management of foreskin conditions [monograph on the Internet]. London: British Association of Paediatric Urologists; 2007 [cited 2008 Aug 25]. http://www.baps. org.uk/documents/circumcision2007.pdf.

2. Cold CJ, Taylor JR. The prepuce. Br J Urol. 1999;83(Suppl 1):34-44.

3. Alanis MC, Lucidi RS. Neonatal circumcision: a review of the world's oldest and most controversial operation. Obstet Gynecol Surv. 2004;59(5):379-395.

4. Lerman SE, Liao JC. Neonatal circumcision. Pediatr Clin North Am. 2001;48(6):1539-1557.

5. Williams N, Kapila L. Complications of circumcision. Br J Surg. 1993;80(10):1231-1236.

6. Yilmaz E, Batislam E, Basar MM, Basar H. Psychological trauma of circumcision in the phallic period could be avoided by using topical steroids. Int J Urol. 2003;10(12):651-656.

7. Chessler AJ. Justifying the unjustifiable: rite v wrong. Buffalo Law Rev. 1997;45(2):555-592.

8. Taddio A, Katz J, Ilersich AL, Koren G. Effect of neonatal circumcision on pain response during subsequent routine vaccination. Lancet. 1997;349(9052):599-603.

9. Circumcision of Male Infants Research Paper. Brisbane: Queensland Law Reform Commission; 1993. http://cirp.org/library/legal/QLRC. Accessed Feb 13, 2008.

10. Policy Statement on Circumcision. Sydney: Paediatrics and Child Health Division, Royal Australasian College of Physicians; 2004. http://www.racp.edu.au/index.cfm?objectid = A4254F55-2A57-5487DFE129631BCB4C59. Accessed Feb 28, 2008.

11. Fetus and Newborn Committee, Canadian Paediatric Society. Neonatal circumcision revisited. CMAJ. 1996;154(6):769-780.

12. National Health and Medical Research Council. How to Use the Evidence: Assessment and Application of Scientific Evidence. Canberra (Australia): NHMRC; 2000.

13. Auvert B, Taljaard D, Lagarde E, et al. Randomized, controlled intervention trial of male circumcision for reduction of HIV infection risk: the ANRS 1265 trial. PLoS Med. 2005;2(11):e298.

14. Bailey RC, Moses S, Parker CB, et al. Male circumcision for HIV prevention in young men in Kisumu, Kenya: a randomised controlled trial. Lancet. 2007;369(9562):643-656.

15. Mattson CL, Campbell RT, Bailey RC, Agot K, Ndinya-Achola JO, Moses $S$. Risk compensation is not associated with male circumcision in Kisumu, Kenya: a multi-faceted assessment of men enrolled in a randomized controlled trial. PLoS One. 2008;3(6):e2443.

16. Gray RH, Kigozi G, Serwadda D, et al. Male circumcision for HIV prevention in men in Rakai, Uganda: a randomised trial. Lancet. 2007;369(9562):657-666.

17. Kigozi G, Watya $S$, Polis CB, et al. The effect of male circumcision on sexual satisfaction and function, results from a randomized trial of male circumcision for human immunodeficiency virus prevention, Rakai, Uganda. BJU Int. 2008;101(1):65-70. 
18. Kigozi G, Gray RH, Wawer MJ, et al. The safety of adult male circumcision in HIV-infected and uninfected men in Rakai, Uganda. PLOS Med. 2008a;5(6):e116.

19. Macke JK. Analgesia for circumcision: effects on newborn behavior and mother/infant interaction. J Obstet Gynecol Neonatal Nurs. 2001;30(5):507-514.

20. Taddio A, Stevens B, Craig K, Rostogi P, et al. Efficacy and safety of lodocaine-prilocaine cream for pain during circumcision. New Engl J Med. 1997;336:1197-1201.

21. Krieger JN, Bailey RC, Opeya JC, et al. Adult male circumcision outcomes: experience in a developing country setting. Urol Int. 2007;78(3):235-240.

22. Mills E, Cooper C, Anema A, Guyatt G. Male circumcision for the prevention of heterosexually acquired HIV infection: a metaanalysis of randomized trials involving 11,050 men. HIV Med. 2008;9(6):332-335

23. Kapila L, Burr S, Dodd K, et al. Statement on Male Circumcision. London: Royal College of Surgeons of England; 2001. http://www. baps.org.uk/documents/Circumcision\%20statement\%20RCS.htm. Accessed Feb 20, 2008.
24. Weiss H, Polonsky J. Male Circumcision: Global Trends and Determinants of Prevalence, Safety and Acceptability. Geneva: UNAIDS; 2007 http://www.who.int/hiv/topics/malecircumcision/JC1320_MaleCircumcision_Final_UNAIDS.pdf. Accessed Feb 29, 2008.

25. Macdonald A, Humphreys J, Jaffe HW. Prevention of HIV transmission in the UK: what is the role of male circumcision? Sex Transm Infect. 2008;84(3):158-160.

26. Inungu J, MaloneBeach $E$, Betts J. Male circumcision and the risk of HIV infection. AIDS Read. 2005;15(3):130-131, 135, 138

27. Weiss HA, Thomas SL, Munabi SK, Hayes RJ. Male circumcision and risk of syphilis, chancroid, and genital herpes: a systematic review and meta-analysis. Sex Transm Infect. 2006;82(2):101-109, discussion 110.

28. Van Howe RS. Does circumcision influence sexually transmitted diseases? A literature review. BJU Int. 1999;83(Suppl 1):55-62.

29. Siegfried N, Muller M, Volmink J, et al. Male circumcision for prevention of heterosexual acquisition of HIV in men. Cochrane Database Syst Rev. 2003;(3)CD003362.

\section{CHANCE-OF-ADDRESS FORM FAMNILY MEDICINE}

Please complete this form and mail to the following address or fax to Annals Circulation at 913-906-6080:

Annals of Family Medicine, Circulation Department, 11400 Tomahawk Creek Pkwy, Leawood, KS 66211-2680

Check if member of sponsoring organization:

$$
\begin{array}{lc}
\square \text { AAFP } & \square \text { ABFM } \square \text { STFM } \square \text { ADFM } \\
\square \text { AFMRD } & \square \text { NAPCRG } \square \text { CFPC }
\end{array}
$$

ID number from label on your journal cover

OLD Information (Please print.)

Name

Company (if applicable)

Address (Street plus Apt or Ste)

\begin{tabular}{ll}
\hline City & State \\
\hline Country & Postal Code (9-digit ZIP for US) \\
\hline Telephone & Fax \\
\hline E-Mail &
\end{tabular}

NEW Information (Please print.)

\begin{tabular}{ll}
\hline Name \\
\hline Company (if applicable) \\
\hline Address (Street plus Apt or Ste) & \\
\hline City & Postal Code (9-digit ZIP for US) \\
\hline Country & Fax \\
\hline E-Mail &
\end{tabular}

